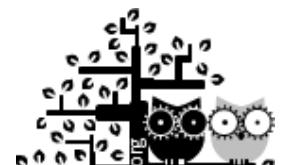

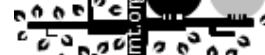 \\ $00000^{2} 0^{\circ}$ \\ 0 范 000 \\ cno \\ auSMT:
}

\section{Applying Hybrid-Quantity Analysis in the Asia Semiconductor Industry}

\section{Chin-Yuan Fan*, Ming-Fong Lai, and Shu-Hao Chang}

Science and Technology Policy Research and Information Center of National Applied Research Laboratories, Taiwan

(Received 15 November 2012; Accepted 28 January 2013; Published on line 1 September 2013)

*Corresponding author: cyfan@stpi.narl.org.tw

DOI: $10.5875 /$ ausmt.v3i3.174

Abstract: The semiconductor market has gradually transitioned from advanced countries to the Asian-Pacific region. Since the 1980s, Taiwan has been developing its own semiconductor industry, and after 20 years of effort, has become one of the world's major exporters of semiconductor products. Therefore, to position Taiwan in relation to other countries for competitive advantage, as defined by technology and industrial development, requires a better understanding of the developmental trends of the semiconductor technology of major competing countries in the Asian-Pacific region. This can further provide the Taiwanese government with additional strategic development proposals. We used a combination of patents, data-mining methods [multidimensional scaling (MDS) analysis, and K-means clustering] to explore competing technological and strategic-group relationships within the semiconductor industry in the Asian-Pacific region. We assessed the relative technological advantages of various organizations and proposed additional technology development strategy recommendations to the Taiwanese semiconductor industry.

Keywords: Semiconductor industry; patent-technology analysis; multidimensional scaling; k-means clustering

\section{Introduction}

Manufacturing industries have gradually transferred from advanced countries to the Asian-Pacific region. The manufacturing centers of the semiconductor industry have also transferred from Europe and the United States to Taiwan, South Korea, and China. Advanced countries have shifted their semiconductor-manufacturing bases to the Asian-Pacific region and have actively applied for patents related to manufacturing and R\&D technologies. The large-scale transfer of core technologies to the Asian-Pacific region aims to make profits and save production costs, while further enhancing the R\&D capabilities of the semiconductor industry.

We discuss how to effectively use systematic search methods in conjunction with multivariable models to conduct patent analysis and to further explore the following research objectives:

(a) Adopt a technology-positioning approach to analyze the strengths and weaknesses of the semiconductor industry in the Asian-Pacific region compared to the technologies of advanced countries.

(b) Assist members of the semiconductor industries in the Asian-Pacific region to face various technology barriers, and further analyze and evaluate how to strengthen the competitive advantage of the Taiwanese semiconductor industry.

\section{Introduction to the Semiconductor Industry}

Characteristics of the Semiconductor Industry in the Asian-Pacific Region

From the beginning of the twenty-first century, the growth of the semiconductor industry in the Asian-Pacific region has become the focus of considerable attention. According to an analysis by [1], in $2008,43 \%$ of the total world production of electronic products was conducted in the Asian-Pacific region; a figure that is expected to rise to $50 \%$ by 2012 . The growth of semiconductors, 
which form the core of electronic products, has been tremendous. According to a study conducted by the U.S. Semiconductor Industry Association (SIA), from 2004 to 2008 , sales in the Asian-Pacific region were expected to experience an overall growth rate of $69 \%$, with the amount of revenue in 2008 alone reaching USD150.4 billion. Of the various markets worldwide, the overall growth in the Asian-Pacific region is the highest.

Further analysis of this phenomenon indicates that other than Japan, which developed its semiconductor industry at an earlier period, investment by South Korea and Taiwan only commenced in the late twentieth century. The South Korean semiconductor strategy was mainly based on national government supervision, which pushed companies to expand from the top-down within a limited time period. The government provided maximum support by allocating a massive amount of funds to pay for the enormous costs involved. This development approach was similar to that of Japan and the United States, and is considered an integrated-development strategy. A company that falls under such a strategy is known as an integrated-device manufacturer [2]. In contrast, the Taiwanese government adopted a different approach, emphasizing the principle of original-equipment manufacturing (OEM). The government has also stratified the division of labor of the semiconductor industry's vertical-integration manufacturing process into five sub-industries, including design, photo-masking, manufacturing, packaging, and testing. The division of labor is based on the industry type. Each of these development strategies has its own advantages and disadvantages. South Korea's semiconductor industry-development strategy rises and falls frequently as it follows the cyclical movement of various economic and political factors. Thus, such an

Chin-Yuan Fan received his Ph.D. degree from Yuan- Ze University, Taoyuan, Taiwan, in 2008. He is currently an associate researcher at the STPI, National Applied Research Laboratories, Taipei, Taiwan, (R.O.C.). His current research interests include science-technology strategy analysis, patent analysis, forecasting, case-based reasoning, and soft-computing applications. He is the author and co-author of more than 20 papers published in international journals, including the journal of Expert System with Applications, the International Journal of Production Economics and the Journal of Applied soft-Computing.

Ming-Fong Lai is an associate researcher of Management Information Systems and Patent Analysis for the Science and Technology Policy Research and Information Center (STPI) of National Applied Research Laboratories (NARL), Taipei, Taiwan, (R.O.C.). He earned his Ph.D. at National Taiwan University of Science and Technology (NTUST) and researches knowledge management and strategic information systems for R\&D activities. Dr. Lai also serves as a member of the editorial board for the Business Process Management Journal (BPMJ).

Shu-Hao Chang is an associate research fellow at the STPI, National Applied Research Laboratories, Taipei, Taiwan. His research interests include technology policy, patent analysis, strategy management, and consumer behavior. overall development strategy is greatly influenced by the government and a few large enterprises. However, the overall developmental advantage of such a strategy is the synergy created, which is why the semiconductor industry in South Korea has the most competitive market prices. Using the South Korean semiconductor industry's most concentrated memory-chip development as an example, in a situation where memory-chip oversupply in the market has already caused profit contractions, strong government support and corporate economies-of-scale allow South Korean memory-chip manufacturers to maintain profitability $[3,4]$.

The South Korean semiconductor-development strategy requires enormous capital and a completely integrated upstream/downstream system to work. This type of strategy is currently used less in Asia-Pacific countries. The semiconductor-industry development strategy of Taiwan has higher flexibility, and the requirement for an integrated upstream/downstream system is less critical. Other Asian-Pacific countries, such as Singapore, Malaysia, and China, currently favor using this type of development model. Although this type of development strategy has lower-entry barriers, its ability to develop technologies that can achieve market economies-of-scale is more problematic. Therefore, discussing and integrating the technologies of Asian-Pacific countries is worthy of further analysis and assessment.

\section{Technical Analysis of the Semiconductor Industry}

The technical analysis method in this study is mainly derived from the analytical methods by [5-7]. We first performed a quick breakdown of the technical analysis characteristics of the semiconductor industry. Because the technical characteristics of the semiconductor industry are complex, finding an appropriate categorization method for effective technical-industry classification is the main study focus. After determining the research object by expert analysis, we adopted the International Patent Classification (IPC) method of [6], combined with the revealed patent advantage (RPA) analysis method by [5] to conduct analysis to identify appropriate technology positioning. We then used this positioning to assist manufacturers in Asian-Pacific countries in technical analysis, and to assess the objectives and strategic planning for future development of the semiconductor industry by Taiwanese manufacturers.

Numerous researchers have attempted to use patent-clustering analysis to solve different types of problems. [8] incorporated an ontology schema to extract and represent patent concepts. They proposed a clustering algorithm with non-exhaustive overlaps to 
overcome the deficiencies of exhaustive-clustering methods used in patent mining and technology discovery. [9] proposed a novel hierarchical-clustering approach for knowledge-document self-organization, particularly for patent analysis. These two methods improve the current keyword-based methodologies for the patent-document content management of technical content that is used for cluster analysis. The hierarchical-clustering approach automatically interprets and clusters knowledge documents more effectively than traditional keyword methods. However, these methods require powerful text-mining programming ability and an understanding of machine-learning algorithms and are too difficult for general researchers to understand.

\section{Methodology}

\section{Methodology Process}

We conducted a literature discussion and secondary-data collection to determine the analysis targets. We then proceeded to conduct a comprehensive patent search. After classifying the retrieved patent-search information according to the patentee and IPC country of origin, we totaled the number of patents in each IPC category from each country. To calculate the comparative technological advantage of each country, we classified the patent information according to IPC standards, calculated corresponding patent counts, and converted them into a relative RPA index to represent the relative strength of different countries in various technology categories. Finally, we used the quantitative-dimension reduction of the multidimensional scaling (MDS) analysis technique and K-means clustering classification to obtain the position status within the technology category. The procedure is shown in Figure 1.

\section{Multi-Dimensional Scaling and K-means Clustering} Analysis

We used MDS analysis to explore the semiconductor technology-development positioning and strategic groupings of five countries. The analysis used $\mathrm{N}$ number of subjects, based on $\mathrm{P}$ number of criteria, to assess $M$ number of objects for using spatial positions in observed values after clustering to conduct a perceptual-positioning analysis $[2,10,11]$. The original data and spatial degree of adaptability were reflected by stress coefficients. The smaller a stress coefficient is, the better the degree of adaptability, which often reduces the dimensions to 2 or 3D space. We applied K-means analysis for the adjacent points in space, according to data-point similarity, to determine strategic grouping.

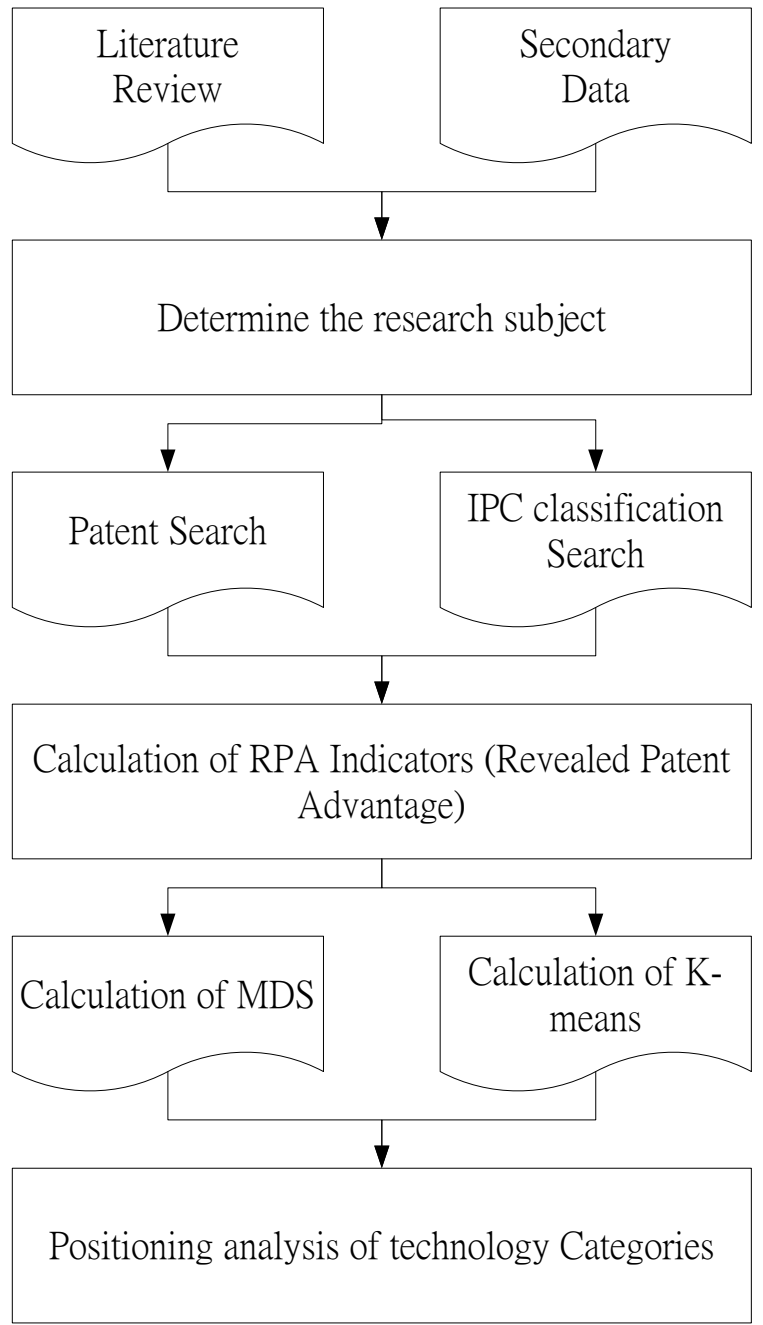

Figure 1. Research Process.

\section{Research Results}

\section{Patent Search Results}

The patent data was derived from the Worldwide Patent Statistical Database (PatSTAT), which contains 20 million items of patent information. We used USPTO-approved patent information from January 1976 to December 2009. The content includes the International Patent Classification IPC, name of patent, patent application date, patent publication date, patent approval date, patent category, patent inventor, and patent authority.

We used the eighth edition of the IPC system. Writing uppercase letters $\mathrm{A}-\mathrm{H}$ in English is conventional to represent all IPC knowledge domains. " $\mathrm{H}$ " is the section in which semiconductor technology belongs within "Electricity." We used patent information to match to the research scope. Table 1 presents an explanation of the meaning of the various patent categories. Detail information can be shown at (http://www.wipo.int/ipc/itos4ipc/ITSupport_and_downl 
oad area/20100101/definitions viewer/en/en 2010010 1 definitions viewer.htm); Table 2 shows the results after compilation.

\section{Revealed Patent Advantage}

Because R\&D strategies differ among countries, strictly identifying the technological advantage by the number of patents is inappropriate. Therefore, we used the RPA proposed by Schmoch (1995) to evaluate the relative technological advantage of each country, which is defined as follows:

$$
R P A_{i j}=100 \tanh / n\left[\left(P_{i j} / \sum_{i} P_{i j}\right) /\left(\sum_{j} P_{i j} / \sum_{i} \sum_{j} P_{i j}\right)\right],
$$

where $P_{i j}$ is the number of patents from $j^{\text {th }}$ country in $i^{\text {th }}$ patent category, and $\sum_{i} P_{i j}$ represents the total number of patents from $j^{\text {th }}$ country. Therefore, the value of $P_{i j} / \sum_{i} P_{i j}$ represents the importance of the $i^{\text {th }}$ patent category for companies in $j^{\text {th }}$ country. The $\sum_{i} P_{i j}$ represents the total number of patents in the $i^{\text {th }}$ technology category, with $\sum_{i} \sum_{j} P_{i j}$ representing the total number of patents. Therefore, $\sum_{j} P_{i j} / \sum_{i} \sum_{j} P_{i j}$ represents the importance of the $i^{\text {th }}$ technology category to industry technology. Variable
$\left[\left(P_{i j} / \sum_{i} P_{i j}\right) /\left(\sum_{i} P_{i j} / \sum_{i} \sum_{i} P_{i j}\right)\right]$ represents the distribution use of overall industry patents to measure the relative importance of the $i^{\text {th }}$ patent category to the $j^{\text {th }}$ country. However, the difference in the importance level of various technology categories among countries could be large and could form maximum or minimum extreme values, affecting subsequent position analysis. Therefore, we used the In function to manage extreme values and the tanh function to adjust the technology intensity to a value between 1 and -1 . We multiplied the calculated result by 100 , making the final RPA value fall between -100 to 100 .

Finally, we used the RPA value to describe the technological strength of a specific country. Regarding a specific-patent category, its value is bound from -100 to +100. A positive RPA value represents a relatively high technology level. A negative RPA value represents a relatively low technology level. A difference of 15 or more between two RPA values indicates a statistically significant difference between the two technological capabilities. By combining the RPA formula with data shown in Table 2, we obtained 33 types of RPA values in the technology categories of five countries, as shown in Table 3.

Table 1. Definition of IPC Categories [12].

\begin{tabular}{|ll|}
\hline IPC Categories & Meaning \\
\hline H01 & Electricity \\
\hline H01L & Basic electrical components \\
\hline H01L21 & Semiconductor Equipment \\
\hline H01L23 & Sequipment \\
\hline H01L25 & Most single semiconductor devices or other solid components of the assembly \\
\hline H01L27 & $\begin{array}{l}\text { A common substrate formed in or on the number of semiconductors or other solid components of } \\
\text { the device }\end{array}$ \\
\hline H01L29 & Semiconductor devices specially adapted for rectifying, amplifying, oscillating, or switching and \\
having at least one potential-jump barrier or surface barrier; Capacitors or resistors with at least one \\
potential-jump barrier or surface barrier (e.g., PN-junction depletion layer or carrier concentration \\
layer)
\end{tabular}


Table 2. Countries Involved in the Semiconductor-Technology Category and Approved Patents.

\begin{tabular}{|c|c|c|c|c|c|c|}
\hline & Taiwan & Japan & South Korea & China & Singapore & Subtotal \\
\hline H01L21/0 & 6,213 & 25,499 & 4,921 & 52 & 667 & 37,352 \\
\hline H01L21/1 & 11 & 117 & 12 & 0 & 3 & 143 \\
\hline H01L21/2 & 2,110 & 9,828 & 1,804 & 15 & 245 & 14,002 \\
\hline H01L21/3 & 6,252 & 18,917 & 4,747 & 53 & 749 & 30,718 \\
\hline H01L21/4 & 2,769 & 6,757 & 1,872 & 37 & 371 & 11,806 \\
\hline H01L21/5 & 352 & 2,310 & 194 & 4 & 82 & 2,942 \\
\hline H01L21/6 & 1,326 & 8,780 & 771 & 15 & 94 & 10,986 \\
\hline H01L21/7 & 7,102 & 16,011 & 4,554 & 35 & 735 & 28,437 \\
\hline H01L21/8 & 4,256 & 8,689 & 3,041 & 42 & 221 & 16,249 \\
\hline H01L21/9 & 21 & 139 & 10 & 0 & 1 & 171 \\
\hline H01L23/0 & 386 & 2,567 & 233 & 7 & 61 & 3,254 \\
\hline H01L23/1 & 261 & 2,813 & 175 & 1 & 25 & 3,275 \\
\hline H01L23/2 & 439 & 3,233 & 275 & 7 & 65 & 4,019 \\
\hline H01L23/3 & 1,246 & 4,427 & 384 & 53 & 122 & 6,232 \\
\hline H01L23/4 & 2,655 & 15,455 & 1,556 & 48 & 248 & 19,962 \\
\hline H01L23/5 & 1,897 & 10,376 & 1,039 & 16 & 240 & 13,568 \\
\hline H01L23/6 & 390 & 1,042 & 109 & 3 & 34 & 1,578 \\
\hline H01L25/0 & 149 & 1,214 & 74 & 4 & 10 & 1,451 \\
\hline H01L25/1 & 47 & 781 & 61 & 1 & 3 & 893 \\
\hline H01L27/0 & 1,023 & 7,919 & 735 & 23 & 94 & 9,794 \\
\hline H01L27/1 & 2,016 & 12,948 & 2,139 & 24 & 75 & 17,202 \\
\hline H01L27/2 & 44 & 660 & 98 & 0 & 1 & 803 \\
\hline H01L27/3 & 34 & 497 & 82 & 0 & 0 & 613 \\
\hline H01L29/0 & 798 & 7,837 & 1,096 & 18 & 78 & 9,827 \\
\hline H01L29/1 & 208 & 2,139 & 257 & 6 & 9 & 2,619 \\
\hline H01L29/2 & 149 & 1,125 & 102 & 0 & 25 & 1,401 \\
\hline H01L29/3 & 15 & 452 & 20 & 1 & 1 & 489 \\
\hline H01L29/4 & 1,618 & 7,699 & 1,415 & 15 & 184 & 10,931 \\
\hline H01L29/5 & 73 & 594 & 58 & 0 & 20 & 745 \\
\hline H01L29/6 & 866 & 6,944 & 934 & 10 & 71 & 8,825 \\
\hline H01L29/7 & 1,937 & 13,353 & 2,102 & 31 & 147 & 17,570 \\
\hline H01L29/8 & 126 & 1,858 & 104 & 10 & 6 & 2,104 \\
\hline H01L29/9 & 334 & 2,023 & 377 & 5 & 19 & 2,758 \\
\hline Subtotal & 47,123 & 205,003 & 35,351 & 536 & 4,706 & 292,719 \\
\hline
\end{tabular}


Table 3. RPA Value of Technology Categories.

\begin{tabular}{|c|c|c|c|c|c|}
\hline & Taiwan & Japan & Korea & China & Singapore \\
\hline H01L21/0 & 3.269765 & -2.55532 & 8.67928 & -26.7402 & $10.46387^{\#}$ \\
\hline H01L21/1 & -62.8237 & 15.4276 & -34.8778 & 0 & $26.00318^{\#}$ \\
\hline H01L21/2 & -6.59644 & 0.222377 & 6.460257 & -49.0008 & $8.447576^{\#}$ \\
\hline H01L21/3 & 23.02984 & -12.7895 & 24.16733 & -5.94079 & $39.3986^{\#}$ \\
\hline H01L21/4 & 35.95163 & -19.9143 & 26.57506 & 49.1009 & $58.51205^{* \#}$ \\
\hline H01L21/5 & -28.8346 & 11.38506 & -54.0669 & -28.9221 & $50.07069^{\#}$ \\
\hline H01L21/6 & -28.0296 & $13.12811^{\#}$ & -49.5106 & -28.5346 & -55.8539 \\
\hline H01L21/7 & 41.2929 & -21.4827 & 27.49412 & -37.7606 & $44.20686^{\#}$ \\
\hline H01L21/8 & $45.16334^{* \#}$ & -26.3425 & $41.20197^{*}$ & 33.16822 & -16.5707 \\
\hline H01L21/9 & -26.4266 & $14.79059^{\#}$ & -62.0115 & 0 & -76.6295 \\
\hline H01L23/0 & -29.6202 & 11.84822 & -47.9793 & $15.97246^{\#}$ & 15.24115 \\
\hline H01L23/1 & -60.6332 & $20.13336^{\#}$ & -67.2559 & -94.5891 & -63.205 \\
\hline H01L23/2 & -36.9494 & $13.76858^{\#}$ & -51.3985 & -5.00023 & 0.597362 \\
\hline H01L23/3 & 21.33639 & 1.421238 & -58.69 & $91.13905^{* \#}$ & 19.44359 \\
\hline H01L23/4 & -18.8647 & 9.99557 & -41.184 & $26.59026^{\#}$ & -25.222 \\
\hline H01L23/5 & -14.0062 & 8.774364 & -42.6466 & -41.3683 & $9.52547^{\#}$ \\
\hline H01L23/6 & $40.42219^{\#}$ & -5.876 & -50.6997 & 3.751539 & 28.473 \\
\hline H01L25/0 & -42.1578 & 17.60043 & -69.7316 & $38.77255^{\#}$ & -68.9524 \\
\hline H01L25/1 & -80.6868 & $21.85921^{\#}$ & -51.5232 & -45.5606 & -91.6323 \\
\hline H01L27/0 & -40.7474 & 14.27028 & -44.2848 & $24.37933^{\#}$ & -47.4495 \\
\hline H01L27/1 & -30.7207 & $7.197947^{\#}$ & 2.91909 & -26.5385 & -86.2984 \\
\hline H01L27/2 & -79.235 & $15.87203^{\#}$ & 1.04988 & 0 & -98.8071 \\
\hline H01L27/3 & -78.778 & $14.53763^{\#}$ & 10.1886 & 0 & 0 \\
\hline H01L29/0 & -59.4326 & $12.9185^{\#}$ & -7.94125 & 0.0317 & -60.804 \\
\hline H01L29/1 & -60.8514 & 15.25346 & -20.4654 & $22.03708^{\#}$ & -91.2614 \\
\hline H01L29/2 & -39.2324 & $13.59385^{\#}$ & -46.6887 & 0 & 10.39324 \\
\hline H01L29/3 & -92.9928 & $27.05973^{* \#}$ & -79.4214 & 11.00245 & -96.8155 \\
\hline H01L29/4 & -8.37633 & 0.567609 & $6.93019^{\#}$ & -28.0729 & 4.592019 \\
\hline H01L29/5 & -45.9339 & 12.89615 & -41.2861 & 0 & $47.2064^{\#}$ \\
\hline H01L29/6 & -45.8181 & $11.5954^{\#}$ & -13.122 & -44.6183 & -59.9451 \\
\hline H01L29/7 & -36.1492 & $8.155513^{\#}$ & -0.94169 & -3.71097 & -57.3781 \\
\hline H01L29/8 & -75.6877 & 22.7782 & -71.3029 & $74.15092^{\#}$ & -93.8992 \\
\hline H01L29/9 & -27.722 & 4.623129 & $12.32409^{\#}$ & -0.99886 & -68.9734 \\
\hline
\end{tabular}

Note: * Strongest performing country within the category: \# Strongest performing specific-technical category of a country. 
MDS Analysis of Semiconductor-Technology Positioning for Each Country

We first divided the approved patents from the five countries in the semiconductor-technology category into 33 technology categories according to the IPC. However, the highly complex nature of the data hindered clear expression of the positioning of these countries; therefore, we reduced the dimension based on the streamlining principle. This allowed us to fully disclose the technology positioning of each country. Therefore, we used the least squares method of SPSS to perform MDS analysis. The resulting MDS analysis was used as the main analytical tool to use smaller dimensions to explain the relative distance in technological capabilities among countries. The more dimensions used during analysis, the more accurate the information expression of the object under analysis. Analysts must choose between dimension reduction and explanatory power. We only used two dimensions to express the semiconductor-technology positioning of each country, as shown in Figure 2; this explains approximately $78 \%$ of the data variance. The horizontal and vertical axes indicate the two dimensions using this method.

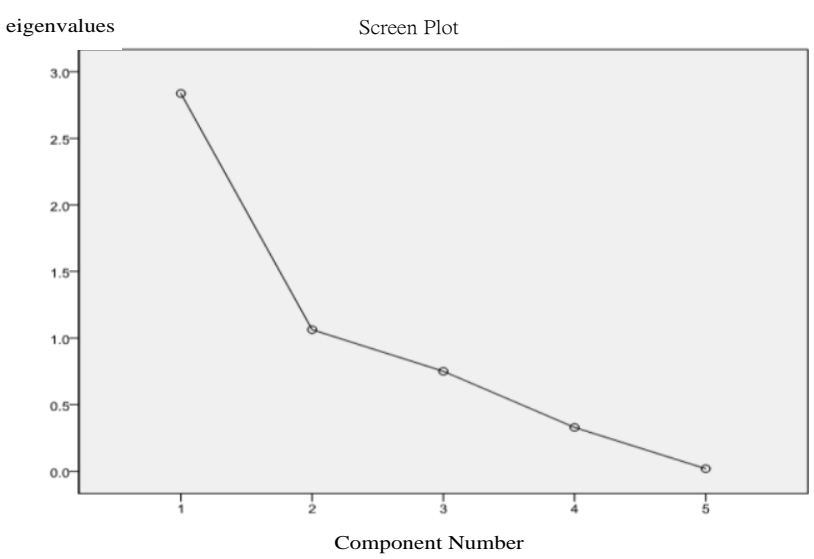

Figure 2. Screen Plot of Dimensions.

\section{Technology Positioning}

We conducted MDS analysis on the RPA indicators of the 33 technology categories in these five countries to estimate the technological-positioning score of each country in 2D space, as shown in Table 4. The patterns of these 33 types of technology categories in technology-positioning space are shown in Table 5. From the obtained score pattern, we drew a perceptual similarity map for the semiconductor-technology development of each country and the layout position of the semiconductor-technology field for the five countries of Taiwan, Japan, South Korea, China, and Singapore, as shown in Figure 3. The technological-positioning diagram adopts the relative capability of each country in various technology categories to analyze the technology-capability similarities of countries and technology categories. Therefore, by projecting each country score on the positioning map as the length of the technology-categorization vector, we derived the original index value representing the relative capability of each country in various technology categories.

Table 4. Semiconductor-Technology Positioning of each Country.

\begin{tabular}{|lll|}
\hline & Horizontal Axis & Vertical Axis \\
\hline Taiwan & 0.951 & 0.1216 \\
\hline Japan & -1.5749 & -0.5156 \\
\hline South Korea & 0.5907 & 1.1122 \\
\hline China & -1.3644 & 0.2224 \\
\hline Singapore & 1.3976 & -0.9406 \\
\hline
\end{tabular}

\section{Analysis of the Main Technology Categories}

We further used the K-means clustering method to group various technology categories according to their strengths using the main technology focus in the semiconductor industry of each country as the clustering criteria. A cluster of four groups reaches a convergence condition where its within-group difference is minimal and its between-group difference is maximal. We also judged it to be a cluster possessing similar resources and implementing similar strategies according to definitions proposed by $[13,14]$. Through interviews with experts and literature review, we effectively defined the 33 technology categories into four groups, which are defined as follows:

Group 1: Semiconductor-component assembly process group. The fourth-order IPC of this group is focused on H01L21 and H01L23, where H01L21 is defined as the patents for semiconductor-manufacturing processes and H01L23 is defined as the patents for semiconductor-component parts. Such a grouping can be used to determine the strengths and weaknesses of the semiconductor-component assembly process. This group is more suitable for determining the capabilities of the semiconductor-manufacturing process.

Group II: Semiconductor-assembly technology group. This group contains H01L21 semiconductor-manufacturing process patents, H01L25 semiconductor-component patents, and H01L29 semiconductor-material patents. The combined characteristics from these three patent groups are more appropriately assigned to the semiconductor-assembly technology group. 
Table 5. Technology Positioning within Technology Categories.

\begin{tabular}{|c|c|c|}
\hline & Horizontal Axis & Vertical Axis \\
\hline H01L210 & 1.3829 & -0.7278 \\
\hline H01L211 & 0.1604 & -0.5825 \\
\hline H01L212 & 0.825 & -1.1028 \\
\hline H01L213 & 2.6961 & -0.0607 \\
\hline H01L214 & 2.7106 & 1.0407 \\
\hline H01L215 & 0.7386 & -0.6127 \\
\hline H01L216 & -1.2713 & -0.3891 \\
\hline H01L217 & 2.3972 & -0.4035 \\
\hline H01L218 & 1.6894 & 1.9113 \\
\hline H01L219 & -1.0907 & 0.3551 \\
\hline H01L230 & 0.1388 & 0.2407 \\
\hline H01L231 & -0.9339 & -1.0554 \\
\hline H01L232 & -0.3861 & -0.6364 \\
\hline H01L233 & 0.8013 & 1.0283 \\
\hline H01L234 & -0.3261 & 0.6787 \\
\hline H01L235 & 0.085 & -1.466 \\
\hline H01L236 & 1.3852 & 0.2297 \\
\hline H01L250 & -0.9061 & 0.7105 \\
\hline H01L251 & -1.3018 & -0.4503 \\
\hline H01L270 & -1.0888 & 0.6036 \\
\hline H01L271 & -0.8466 & 0.3647 \\
\hline H01L272 & -1.1106 & 0.4899 \\
\hline H01L273 & 0.0183 & -0.1346 \\
\hline H01L290 & -1.2561 & 0.2314 \\
\hline H01L291 & -0.9162 & 0.613 \\
\hline H01L292 & -0.2309 & -0.7778 \\
\hline H01L293 & -1.4547 & 0.097 \\
\hline H01L294 & 0.777 & -1.0438 \\
\hline H01L295 & 0.729 & -0.4047 \\
\hline H01L296 & -1.207 & -0.6939 \\
\hline H01L297 & -1.0051 & 0.4067 \\
\hline H01L298 & -0.6307 & 0.7606 \\
\hline H01L299 & -0.5724 & 0.7801 \\
\hline
\end{tabular}
This group contains the four major IPC categories of H01L21, H01L23, H01L25, and H01L29, but only a small amount of IPC. According to IPC analysis, this group leans more toward the design process, and therefore, is defined as the semiconductor-material design group.

Group IV: The component assembly-process technology group includes partial H01L21, H01L23, H01L27, and H01L29 categories. This group is more suitable for use in determining overall integrated manufacturing, and therefore, is considered a packaging-test group.

We also grouped countries, such as Taiwan, Japan, South Korea, China, and Singapore, into four major categories. The first category is the component assembly-process technology of Taiwan and South Korea; the second category is the packaging technology of China; the third category is the material-design technology of Japan; the fourth category is the component assembly-process technology of Singapore. We aggregate the results of MDS and cluster analysis in Figure 3.

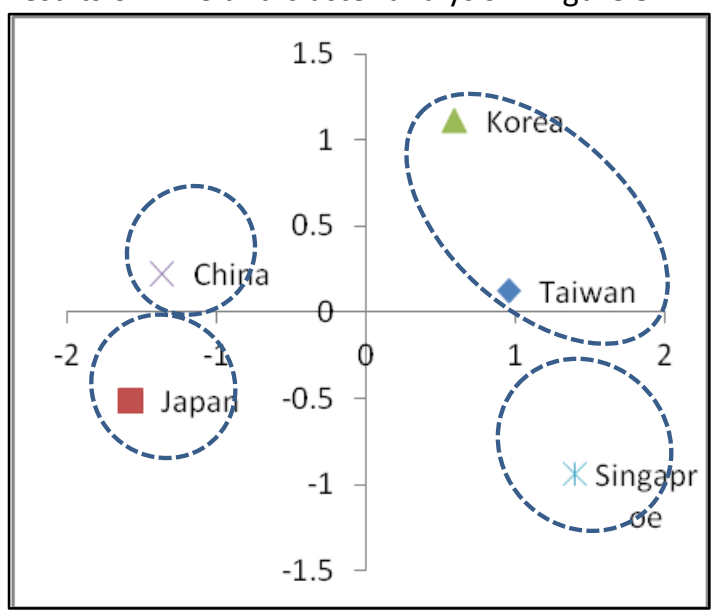

(a) Technological positioning distribution cluster

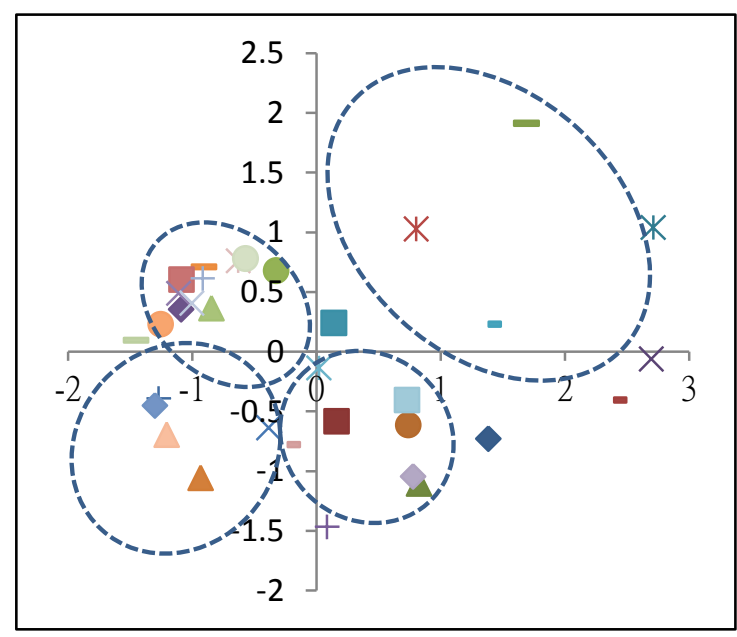

(b) Semiconductor technology

Figure 3. Distribution for Semiconductor Technology-Positioning of each Country. 
Table 6. Countries with Strong-Technology Positions and Expert Opinions.

\begin{tabular}{|c|c|c|}
\hline Country & $\begin{array}{l}\text { Strong technology position } \\
\text { (IPC code) }\end{array}$ & Expert opinions \\
\hline Japan & $\begin{array}{l}\text { H01L29/3 (most significant } \\
\text { technology), H01L21/6, H01L21/9, } \\
\text { H01L23/1, H01L23/2, H01L25/1, } \\
\text { H01L27/1, H01L27/2, H01L27/3, } \\
\text { H01L29/0, H01L29/2,H01L29/6, } \\
\text { H01L29/7(superior technology). }\end{array}$ & $\begin{array}{l}\text { Japan leads Asia in the semiconductor industry; however, it } \\
\text { lost production ability following the } 2011 \text { Tohoku Earthquake. } \\
\text { (http://www.teema.org.tw/english/index.aspx) }\end{array}$ \\
\hline Taiwan & $\begin{array}{l}\text { H01L21/8 (most significant } \\
\text { technology), H01L23/6(superior } \\
\text { technology). }\end{array}$ & $\begin{array}{l}\text { Taiwan excels in IC design, foundry, and packaging and testing, } \\
\text { LED, and other related industries. Foundry and IC packaging } \\
\text { and testing continue to rank first worldwide, IC design ranks } \\
\text { second worldwide. Semiconductor equipment and materials, } \\
\text { and the amount of investment in Taiwan ranked second } \\
\text { worldwide in 2012.( Department of Investment Services, } \\
\text { Ministry of Economic Affairs, 2008) [15] } \\
\text { (http://www.elecsound.cn/news/571.html) }\end{array}$ \\
\hline $\begin{array}{l}\text { South } \\
\text { Korea }\end{array}$ & $\begin{array}{l}\text { HO1L21/8,H01L29/4, H01L29/9 } \\
\text { (superior technology), } \\
\text { No more significant technology } \\
\text { (Korea generally seems very strong } \\
\text { in many areas, however, in this } \\
\text { study this country just shows } \\
\text { superior in many areas, with no } \\
\text { significant technology). }\end{array}$ & $\begin{array}{l}\text { Semiconductor exports in South Korea posted a record high } \\
\text { last month. Their semiconductor market-share worldwide has } \\
\text { also exceeded } 50 \% \text {. According to the Ministry of Knowledge } \\
\text { Economy on September 7, 2010, semiconductor exports in } \\
\text { August set a record high of USD } 4.740 \text { billion, } 64.9 \% \text { higher } \\
\text { than the same period last year. } \\
\text { (http://www.investkorea.org/) }\end{array}$ \\
\hline China & $\begin{array}{l}\text { H01L23/3 (most significant } \\
\text { technology), H01L23/4, H01L25/0, } \\
\text { H01L27/0, H01L29/1, H01L29/8. }\end{array}$ & $\begin{array}{l}\text { Since the late } 1980 \text { s, the Chinese government has attempted } \\
\text { to build an indigenous semiconductor industry by providing } \\
\text { financial incentives, developing talent and technology, and } \\
\text { crafting alliances with global players. Although the country has } \\
\text { assumed a central role in manufacturing numerous computing } \\
\text { and consumer-electronics products, its role in the } \\
\text { semiconductor sector has remained surprisingly limited. In the } \\
\text { industry value chain, China has a strong share in } \\
\text { assembly-and-test and back-end-manufacturing segments. } \\
\text { Aside from these two (admittedly considerable) areas, the } \\
\text { country is largely missing from semiconductor-league tables. } \\
\text { (http://www.mckinsey.com/client service/semiconductors/lat } \\
\text { est thinking/the_challenge of china) }\end{array}$ \\
\hline
\end{tabular}




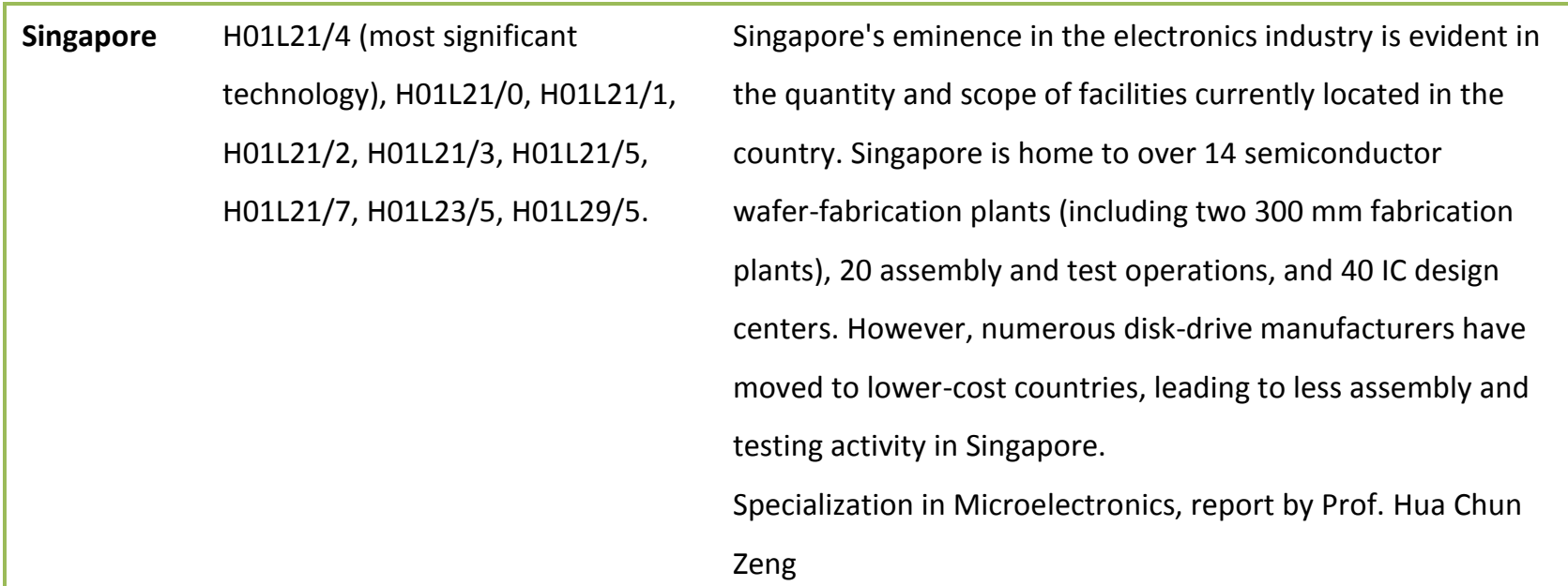

Table 4 shows that each country possesses different technology strengths. For Taiwan that is H01L218, for Japan it is H01L293, for South Korea it is H01L218, for China it is H01L233, and for Singapore it is H01L214. Taiwan and South Korea are technically competing with each other. In addition to H01L218, Taiwan also possesses a technological advantage in H01L236; South Korea is stronger in H01L294 and H01L299. Japan and Singapore have a significant cluster in semiconductor-technology patents. Japan is more concentrated in H01L27, whereas Singapore is more concentrated in the H01L210-H01L215 classes. The technology categories in China that are more prominent have not been mentioned. For example, H01L233, H01L298, or H01L270 are categories that significantly avoid high-patent concentrations.

We conducted further analysis of the strategic implications of the country-based groups. Although Taiwan and South Korea have followed different development strategies, both are included in the same quadrant and the same group cluster, with key development areas toward manufacturing and component design. Examining overall development indicated that Taiwan in Group 1 tended toward Group 4, and South Korea in Group 1 tended toward Group 2. This indirectly shows that Taiwan and South Korea have recently shown different strategies in semiconductor development, with Taiwan moving more toward overall integrated manufacturing and South Korea moving more toward semiconductor-component manufacturing processes. A comparison of the development trends in Taiwan with those of South Korea shows that the Taiwanese semiconductor industry has recently gained certain advantages in assembly testing and manufacture-processing capability. However, it has certain disadvantages in components, including memory chips. South Korean memory manufacturers have excellent market-control ability.
Singapore is closing the gap with Taiwan and South Korea, and shows advantages in integrated manufacturing (packaging and testing) and manufacture processing. However, Singapore has emphasized semiconductor-manufacture processing and packaging, whereas China is emphasizing semiconductor component manufacturing. The two countries have adopted different development strategies for their semiconductor industries. Although certain scholars believe that Taiwan heavily influences the semiconductor industries in both countries, China prefers semiconductor related component manufacturing (e.g., memory chips), whereas Singapore prefers OEM because of the advantage of its geographical location.

Because of the early development of the Japanese semiconductor industry, its application of materials technology and manufacturing is demonstrated by an excellent record in patent publication. The patents produced by Japan are comparable to the patents from the otherfour Asian countries in manufacturing and components. Compared to other countries, Japan tends toward raw-material technology development in upstream-manufacturing supply chains. Earlier patent development results in higher patent numbers.

Numerous semiconductor experts in semiconductor-strategy research have confirmed the accuracy of our experimental research. Following Research Digitimes

(http://www.digitimes.com.tw/tw/rpt/rpt 4.asp?CnlID= 3), these researchers believe that Taiwan and South Korea are similar, and Singapore is closing the gap among them. China leads in semiconductor-component manufacturing and Japan is the Asian winner in the semiconductor industry. The reviewer comments are shown in Table 6. 


\section{Conclusion}

The semiconductor industries in these five Asian countries all have their own specialties. Other than Japan (which developed early and favors material design), the semiconductor patents in the other countries are all concentrated in production and manufacturing. The recently acquired industry upgrade by Taiwan and South Korea is tantamount to a warning message. Improving semiconductor-industry development from production technology toward material-design technology is a critical issue for the other four Asian countries in this study.

Because of its recent integration advantage, South Korea has gradually transitioned to component production from its original manufacturing process. Unlike the unique focus on development in China, South Korea has pursued comprehensive development. Relative to Taiwan, which emphasizes the manufacturing process and integrated testing, South Korea has gradually moved from downstream toward midstream manufacturing. How to improve Taiwanese industrial competitiveness, and how to unleash the advantage of being second in the number of semiconductor patents are worthy questions for semiconductor-industry researchers and government agencies to consider. We suggest that Taiwan take advantage of the opportunity to integrate components from mainland China, while consolidating semiconductor-industry research on both sides of the Taiwan Strait. Further market integration will unleash synergic power, leading to improvements in the Taiwanese semiconductor industry by moving toward upstream-material design.

\section{References}

[1] M. R. Peng, 2008 review and prospect of taiwan's semiconductor industry: Industrial Technology Research Institute, 2008.

[2] R. H. Wu, Y. M. Wang, R. G. Li , and Y. Y. Lu, "A study of market positioning of the industrial furnace systems integration: The application of mds," Sun Yat-Sen Management Review, vol. 13, no. 2, pp. 511-531, 2005.

[3] P. Y. Li, Semiconductor industry yearbook: Industrial Economics and Knowledge Research Center, 2008.

[4] R. W. Ye, "Taiwan semiconductor manufacturing efficiency analysis, department of business and entrepreneurial management," Kainan University, 2009.

[5] U. Schmoch, "Evaluation of technology strategies of companies by means of mds maps," International Journal of Technology Management, vol. 10, no. 4-5, pp. 426-440, 1995. doi: $\underline{10.1504 / I J T M .1995 .025635}$
[6] K. K. Lai and X. J. Wu, Technology positioning of taiwanese semiconductor manufacturers using patent data: Commerce and Management Quarterly, 2004.

[7] L. B. Liu and F. C. Liu, Patent distribution of multinational semiconductor companies and the corresponding strategies of chinese enterprises: East China Economic Management, 2010.

[8] C. V. Trappey, A. J. C. Trappey, and C. Y. Wu, "Clustering patents using non-exhaustive overlaps," Journal of Systems Science and Systems Engineering, vol. 19, no. 2, pp. 162-181, 2010. doi: $10.1007 / \mathrm{s} 11518-010-5134-\mathrm{x}$

[9] A. J. C. Trappey, C. V. Trappey, F. C. Hsu, and D. W. Hsiao, "A fuzzy ontological knowledge document clustering methodology," IEEE Transactions on Systems, Man, and Cybernetics, Part B: Cybernetics, vol. 39, no. 3, pp. 806-814, 2009. doi: 10.1109/TSMCB.2008.2009463

[10] S. Z. Su and Z. Y. Lin, "Marketing review," Marketing Review, vol. 4, no. 2, pp. 221-242, 2007.

[11] Z. Y. Wen, "Application of mds on the analysis of brand perception of taiwanese tea chain stores," in Conference on Innovation of Industry Management, Taichung, 2010

[12] Portal international ipr group, piip, international patent classification (ipc), [Online].

Available: http://www.piip.pro/index.php/zw/database/searc $\underline{\mathrm{h}}$

[13] M. E. Porter, Competitive strategy : Techniques for analyzing industries and competitors. New York: Free press, 1980.

[14] K. J. Hatten and M. L. Hatten, "Strategic groups, asymmetrical mobility barriers and contestability," Strategic Management Journal, vol. 8, no. 4, pp. 329-342, 1987. doi: $10.1002 /$ smj. 4250080404

[15] Analysis of semiconductor industry and investment opportunities, Department of Investment Services, Ministry of Economic Affairs, 2008, [Online]. Available:

http://www.taiwantrade.com.tw/MAIN/resources/ MAIN/TC/ATTACH/industry/15Semicon CN.pdf 